\title{
Differential modulation of thresholds for intracranial self-stimulation by mGlu5 positive and negative allosteric modulators: implications for effects on drug self-administration
}

\author{
Richard M. Cleva ${ }^{1}$, Lucas R. Watterson ${ }^{2}$, Meagan A. Johnson ${ }^{2}$ and M. Foster Olive ${ }^{1,2 *}$ \\ ${ }^{1}$ Interdisciplinary Graduate Program in Neuroscience, Arizona State University, Tempe, AZ, USA \\ ${ }^{2}$ Department of Psychology, Arizona State University, Tempe, AZ, USA
}

\section{Edited by:}

Andrew Lawrence, Florey

Neuroscience Institutes, Australia

Reviewed by:

Athina Markou, University of California San Diego, USA

Jason B. Wu, Cedars-Sinai Medical

Center, USA

\section{${ }^{*}$ Correspondence}

M. Foster Olive, Department of Psychology, Arizona State University, 950 South McAllister Avenue, PO Box 871104, Tempe, AZ 85287-1104, USA. e-mail: foster.olive@asu.edu

\begin{abstract}
Pharmacological manipulation of the type 5 metabotropic glutamate (mGlu5) receptor alters various addiction related behaviors such as drug self-administration and the extinction and reinstatement of drug-seeking behavior. However, the effects of pharmacological modulation of mGlu5 receptors on brain reward function have not been widely investigated. We examined the effects of acute administration of positive and negative allosteric modulators (PAMs and NAMs, respectively) on brain reward function by assessing thresholds for intracranial self-stimulation (ICSS). In addition, when acute effects were observed, we examined changes in ICSS thresholds following repeated administration. Male SpragueDawley rats were implanted with bipolar electrodes into the medial forebrain bundle and trained to respond for ICSS, followed by assessment of effects of mGlu5 ligands on ICSS thresholds using a discrete trials current-intensity threshold determination procedure. Acute administration of the selective mGlu5 NAMs MTEP $(0,0.3,1$, or $3 \mathrm{mg} / \mathrm{kg})$ and fenobam $(0,3,10$, or $30 \mathrm{mg} / \mathrm{kg})$ dose-dependently increased ICSS thresholds $(\sim 70 \%$ at the highest dose tested), suggesting a deficit in brain reward function. Acute administration of the mGlu5 PAMs CDPPB $(0,10,30$, and $60 \mathrm{mg} / \mathrm{kg})$ or $\operatorname{ADX} 47273(0,10,30$, and $60 \mathrm{mg} / \mathrm{kg}$ ) was without effect at any dose tested. When administered once daily for five consecutive days, the development of tolerance to the ability of threshold-elevating doses of MTEP and fenobam to increase ICSS thresholds was observed. We conclude that mGlu5 PAMs and NAMs differentially affect brain reward function, and that tolerance to the ability of mGlu5 NAMs to reduce brain reward function develops with repeated administration. These brain reward deficits should be taken into consideration when interpreting acute effects of mGlu5 NAMs on drug self-administration, and repeated administration of these ligands may be an effective method to reduce these deficits.
\end{abstract}

Keywords: mGluR5, glutamate, allosteric modulator, intracranial self-stimulation, brain reward

\section{INTRODUCTION}

The type 5 metabotropic glutamate (mGlu5) receptor has been implicated in numerous CNS functions including synaptic plasticity, learning and memory, cognition, nociception, affect regulation, and motivated behaviors (Niswender and Conn, 2010). mGlu5 receptors are also involved in numerous CNS diseases such as depression, anxiety, schizophrenia, epilepsy, chronic pain, Fragile X syndrome, and drug addiction (Spooren et al., 2001; Bird and Lawrence, 2009a,b; Krystal et al., 2010; Niswender and Conn, 2010). With regards to drug addiction, genetic deletion of the mGlu5 receptor in mice results in indifference to the reinforcing and locomotor stimulant effects of cocaine (Chiamulera et al., 2001) and reduced ethanol consumption (Bird et al., 2008). In addition, a substantial literature exists with a general consensus that negative allosteric modulation of mGlu5 receptors reduces self-administration of most drugs of abuse including cocaine, heroin, methamphetamine, nicotine, and ethanol, as well as the reinstatement of drug-seeking behavior (reviewed in Kenny and Markou, 2004; Bird and Lawrence, 2009b; Olive, 2009; Cleva and Olive, in press).

The mechanism by which pharmacological antagonism of mGlu5 receptors reduces drug intake is not well understood. Several recent studies have demonstrated that a potential site of action of mGlu5 antagonists in reducing drug intake is the nucleus accumbens (Cozzoli et al., 2009; Gass and Olive, 2009b; Besheer et al., 2010), a primary component of the brain's reward circuitry. A well-established method for assessing brain reward circuitry function is the intracranial self-stimulation (ICSS) paradigm, where animals are trained to perform an operant response in order to obtain electrical stimulation of the medial forebrain bundle (Kornetsky and Esposito, 1979; Kornetsky and Bain, 1992; Markou and Koob, 1992). Antagonism of mGlu5 receptors with the negative allosteric modulator (NAM) 2-methyl6-(phenylethynyl) pyridine (MPEP) was first demonstrated to 
reduce thresholds for ICSS by Harrison et al. (2002). These findings were subsequently replicated by Kenny et al. $(2003,2005)$ who advanced the hypothesis that inhibition of mGlu5 receptor function may reduce cocaine self-administration by reducing brain reward function. Although MPEP has typically been the prototypical ligand of choice in many studies for inhibiting mGlu5 receptor function, some studies have revealed that this ligand has off-target effects on NMDA receptors, monoamine oxidase, and the norepinephrine transporter (O'Leary et al., 2000; Heidbreder et al., 2003; Lea and Faden, 2006). More recently, mGlu5 receptor NAMs that exhibit increased selectivity for mGlu5 receptors with fewer off-target effects have been developed, including 3-((2-methyl-4-thiazolyl)ethynyl)pyridine (MTEP; Cosford et al., 2003) and 1-(3-chlorophenyl)-3-(3-methyl-5-oxo-4H-imidazol2-yl)urea (fenobam; Porter et al., 2005; Montana et al., 2009).

Conversely, systemically active positive allosteric modulators (PAMs) of mGlu5 such as 3-cyano- $\mathrm{N}-(1,3$-diphenyl- $1 \mathrm{H}$ pyrazol-5-yl)benzamide (CDPPB; Lindsley et al., 2004; Kinney et al., 2005) and (S)-(4-fluoro-phenyl)-(3-[3-(4-fluoro-phenyl)[1,2,4]-oxadiazol-5-yl]piperidin-1-yl)methanone (ADX47273; Liu et al., 2008) have been developed as novel cognition enhancing agents and potential novel treatments for schizophrenia (Niswender and Conn, 2010). Studies by our laboratory and others have shown that CDPPB facilitates the extinction of cocaine-seeking behavior following intravenous self-administration (Cleva et al., 2011; Nic Dhonnchadha and Kantak, 2011) as well as the extinction of a cocaine-induced conditioned place preference (Gass and Olive, 2009a). However, no studies to date have examined the effects of mGlu5 PAMs on brain reward function.

The goals of the present study were to (1) determine if the more recently developed mGlu5 NAMs MTEP and fenobam, at doses that have been shown to reduce self-administration of drugs of abuse, produce decrements in brain reward function as indicated by increases in ICSS thresholds, (2) determine if mGlu5 PAMs alter brain reward function, and (3) determine if any observed effects of mGlu5 PAMs or NAMs on brain reward function would change after repeated administration, which would be more relevant to clinical use of such ligands.

\section{MATERIALS AND METHODS \\ ANIMALS}

Male Sprague-Dawley rats (250-275g upon arrival) that were obtained from Harlan Laboratories (Indianapolis, IN, USA) were used for this study. Food and water were freely available at all times except during behavioral testing. The animal housing room was maintained on a reversed $12 \mathrm{~h}$ light-dark cycle (lights off at $0800 \mathrm{~h}$ ), with controlled temperature and humidity within NIH guidelines. All experimentation was conducted during the dark phase of the light-dark cycle. All experimental procedures conformed to the 2003 Guide for the Care and Use of Mammals in Neuroscience and Behavioral Research, and were approved by an Institutional Animal Care and Use Committee.

\section{SURGICAL PROCEDURES}

Animals were anesthetized with isoflurane $(2 \% \mathrm{v} / \mathrm{v})$ vaporized in oxygen at a flow rate of $21 / \mathrm{min}$ and placed in a stereotaxic frame (Stoelting Co., Wood Dale, IL, USA). The skin overlying the skull was shaved and scrubbed with betadine and $0.1 \% \mathrm{v} / \mathrm{v} \mathrm{H}_{2} \mathrm{O}_{2}$, and an incision was made to expose the skull surface. A bipolar electrode (\#MS303/2, Plastics One, Roanoke, VA, USA) was then unilaterally implanted into the lateral hypothalamus (AP: $-0.5, \mathrm{ML}: \pm 1.7, \mathrm{DV}$ : $-8.3 \mathrm{~mm}$ from skull surface and bregma according to the atlas of Paxinos and Watson, 2007). The length of the electrode (10 mm) was insulated except at the ventral tip. Electrodes were secured to the skull with stainless steel screws and dental cement. The wound was then treated with $2 \%$ bacitracin/polymyxin B/neomycin and $5 \%$ xylocaine, and sutured closed with 3-0 Vicryl sutures. Animals received meloxicam $(10 \mathrm{mg} / \mathrm{kg}$ s.c. $)$ once daily for 5 days to minimize post-surgical pain and discomfort, and were allowed to recover for at least 5 days prior to ICSS training.

\section{ICSS TESTING APPARATUS}

Intracranial self-stimulation procedures were conducted in computer-interfaced behavioral testing chambers (ENV-007, $30.5 \mathrm{~cm} \times 30 \mathrm{~cm} \times 17 \mathrm{~cm}$, Med Associates. St. Albans, VT, USA) housed in melamine sound-attenuating cubicles as described above. Each chamber contained a metal wheel manipulandum ( $5 \mathrm{~cm}$ wide), centered on one of the side walls, that required $\sim 0.2 \mathrm{~N}$ force to result in a quarter turn rotation. Electrical brain stimulation was delivered by constant current stimulators (Med Associates) controlled by MED-PC IV software. Animals were connected to the stimulators with bipolar leads (Plastics One) attached to gold-contact electrical commutators (model SL2C, Plastics One) mounted on counterbalanced lever arms located atop the chamber.

\section{ICSS PROCEDURES}

A discrete trials current-intensity threshold procedure was employed (Kornetsky and Esposito, 1979; Kornetsky and Bain, 1992; Markou and Koob, 1992) to determine ICSS thresholds. Animals were first trained to turn the wheel manipulandum onequarter of a turn in order to receive a delivery of a 200-ms train of cathodal square-wave pulses (frequency $100 \mathrm{~Hz}$, intensity $120 \mu \mathrm{A}$ ) on a fixed-ratio 1 (FR1) schedule of reinforcement. Training was conducted in 30 min daily sessions. Following successful acquisition of responding for stimulation (>100 reinforcements per $5 \mathrm{~min}$ ), training on the discrete trials current-intensity threshold procedure commenced. Each trial began with a responseindependent delivery of an electrical stimulus (see above for parameters), followed by a 7.5-s period during which the animal was given the opportunity to make a response to receive an identical stimulus. A response during this $7.5 \mathrm{~s}$ period was labeled as a positive response and was followed by a 2 -s timeout period, whereas a lack of a response during this period was labeled as a negative response. Additional responses during the 2-s timeout period resulted in an additional $12.5 \mathrm{~s}$ delay of the onset of the next trial. The inter-trial interval (ITI) that followed either a positive response or the end of the 7.5-s period (in the case of a negative response) was $10 \mathrm{~s}$ in duration. Responses that occurred during the ITI had no consequences.

Animals were subsequently tested on the current-intensity threshold procedure in which stimulation intensities were varied according to the psychophysical method of limits. A test session consisted of five alternating series of descending and ascending 
current intensities, starting with a descending series. Blocks of five trials were conducted at a given stimulation intensity starting at $120 \mu \mathrm{A}$, and the current-intensity was changed by $5 \mu \mathrm{A}$ steps between blocks of trials. Each test session typically lasted 30-40 min. To determine the current-intensity threshold for each animal, the stimulus intensity between the successful completion of a set of trials (positive responses during three or more of the five trials) and the stimulus intensity for which the animal failed to respond positively on two or more of the five trials were recorded. The mean of the thresholds for the five series was defined as the threshold for the session. The time between the beginning of the response-independent stimulation and a positive response was recorded as the response latency for each trial. No response latencies were determined from negative response trials. The response latency for each session was defined as the mean response latency for all trials with positive responses.

\section{DRUGS AND TREATMENT}

MTEP hydrochloride was obtained from Ascent Scientific (Princeton, NJ, USA) and was dissolved in a vehicle consisting of distilled water. Fenobam, CDPPB, and ADX47273 were custom synthesized by Chemir Analytical Services (Maryland Heights, MO, USA) according to previously published methods (Lindsley et al., 2004; Kinney et al., 2005; Porter et al., 2005; Liu et al., 2008) and were suspended in a vehicle consisting of $0.3 \% \mathrm{v} / \mathrm{v}$ Tween 80 (Sigma-Aldrich, St. Louis, MO, USA). Drug treatment procedures commenced following stabilization of baseline currentintensity thresholds (approximately five to seven discrete trial sessions, $<10 \%$ variability in absolute ICSS threshold values). mGlu5 ligands were administered via the s.c. route in a volume of $1 \mathrm{ml} / \mathrm{kg} 20 \mathrm{~min}$ prior to discrete trial current-intensity threshold determinations.

For acute dose response studies, a minimum of two drugfree days of regular ICSS threshold determination testing were conducted between dose, and each dose and vehicle were given in a randomized counterbalanced manner. Doses of each compound administered were as follows: $\operatorname{MTEP}(0.3,1$, or $3 \mathrm{mg} / \mathrm{kg})$, fenobam $(3,10$, or $30 \mathrm{mg} / \mathrm{kg}), \operatorname{CDPPB}(10,30$, and $60 \mathrm{mg} / \mathrm{kg})$, and ADX47273 (10,30, and $60 \mathrm{mg} / \mathrm{kg})$. Separate groups of animals were utilized for each compound administered.

For repeated administration studies, doses of MTEP and fenobam that were found to elevate ICSS thresholds (3 and $30 \mathrm{mg} / \mathrm{kg}$, respectively) were administered once daily for five consecutive days, each given 20 min prior to threshold determination procedures. Separate groups of animals were utilized for each compound administered.

\section{HISTOLOGY}

Animals were deeply anesthetized with sodium pentobarbital, $150 \mathrm{mg} / \mathrm{kg}$ i.p. and perfused transcardially with $100 \mathrm{ml}$ of phosphate-buffered saline (PBS, $\mathrm{pH}=7.4$ ) followed by $200 \mathrm{ml}$ $4 \% \mathrm{w} / \mathrm{v}$ paraformaldehyde in $\mathrm{PBS}(\mathrm{pH}=7.4)$. Brains were then removed, post-fixed at $4^{\circ} \mathrm{C}$ for $24 \mathrm{~h}$, and placed in a $30 \% \mathrm{w} / \mathrm{v}$ sucrose in PBS cryoprotectant solution at $4^{\circ} \mathrm{C}$ for $48 \mathrm{~h}$. Brains were then cut into $40 \mu \mathrm{m}$ sections on a cryostat (Model CM1900, Leica Microsystems, Bannockburn, IL, USA), mounted onto gelatincoated microscope slides, and stained using cresyl violet. The tip of the electrode was then verified to localized to the lateral hypothalamus under light microscopy. Data from animals with incorrect placement of the electrode were excluded from analysis.

\section{DATA ANALYSIS}

Data were analyzed using SigmaPlot software (Version 12.0, Systat Software, San Jose, CA, USA). ICSS thresholds from individual animals were calculated from three consecutive pre-treatment sessions that showed $<10 \%$ variability in current-intensity thresholds, and these values were averaged to obtain a baseline threshold value. ICSS thresholds obtained from the remaining sessions were transformed to a percentage of this baseline value for each individual animal. Effects of acute administration of vehicle or mGlu5 PAMs and NAMs and response latencies were analyzed by oneway between-subjects ANOVA, with drug dose as the main factor, followed by Holm-Sidak post hoc pairwise comparisons against values from vehicle treated animals. Effects of repeated administration of the $3-\mathrm{mg} / \mathrm{kg}$ dose of MTEP and the $30-\mathrm{mg} / \mathrm{kg}$ dose of fenobam on ICSS thresholds were analyzed by one-way repeatedmeasures ANOVA, with treatment day as the main factor, followed by Holm-Sidak post hoc pairwise comparisons against threshold values from the first day of treatment. $P<0.05$ was considered statistically significant for all tests performed. All data are presented as mean \pm SEM.

\section{RESULTS \\ ACUTE DOSE RESPONSE FOR MGLU5 NAMs AND PAMs}

Prior to commencement of treatment, baseline ICSS thresholds were $90.11+6.90 \mu \mathrm{A}$ (mean \pm SEM). The effects of vehicle and $\operatorname{MTEP}(0.3,1$, or $3 \mathrm{mg} / \mathrm{kg})$ and fenobam $(3,10$, and $30 \mathrm{mg} / \mathrm{kg}$ ) on ICSS thresholds are shown in Figures 1A,B. A significant effect of MTEP dose was observed $\left[F_{(3,31)}=10.82, P<0.001\right]$, and post hoc analyses revealed that the $3-\mathrm{mg} / \mathrm{kg}$ dose of MTEP produce a significant $(\sim 70 \%)$ increase in ICSS thresholds as compared to those following vehicle treatment $(P<0.05)$. Similarly, a significant effect of fenobam dose was observed $\left[F_{(3,28)}=3.18, P<0.05\right]$, and post hoc analyses revealed that the $30-\mathrm{mg} / \mathrm{kg}$ dose of fenobam produced a significant ( $\sim 68 \%)$ increase in ICSS thresholds as compared to those following vehicle treatment $(P<0.05)$. MTEP and fenobam did not produce significant effects on response latencies during the discrete trials $(P>0.05$ vs. vehicle).

The effects of vehicle and the 10-, 30-, and 60-mg/kg doses of CDPPB and ADX47273 on ICSS thresholds are shown in Figures 2A,B. None of the doses tested for either mGlu5 PAM produced a significant effect on ICSS thresholds or response latencies (all Ps $>0.05$ vs. vehicle). Due to the lack of effects observed with these compounds, further investigation with repeated administration was not conducted.

\section{EFFECTS OF REPEATED ADMINISTRATION OF MTEP AND FENOBAM}

The effects of repeated (once daily for five consecutive days) administration of the threshold-elevating doses of MTEP $(3 \mathrm{mg} / \mathrm{kg})$ and fenobam $(30 \mathrm{mg} / \mathrm{kg})$ on ICSS thresholds are shown in Figures 3A,B. Effects of repeated administration of vehicle are shown in Figure 3C. In MTEP treated animals, a significant effect of session was observed $\left[F_{(4,43)}=3.97, P<0.01\right]$, and post hoc analyses revealed that ICSS thresholds during sessions 4 and 5 were 


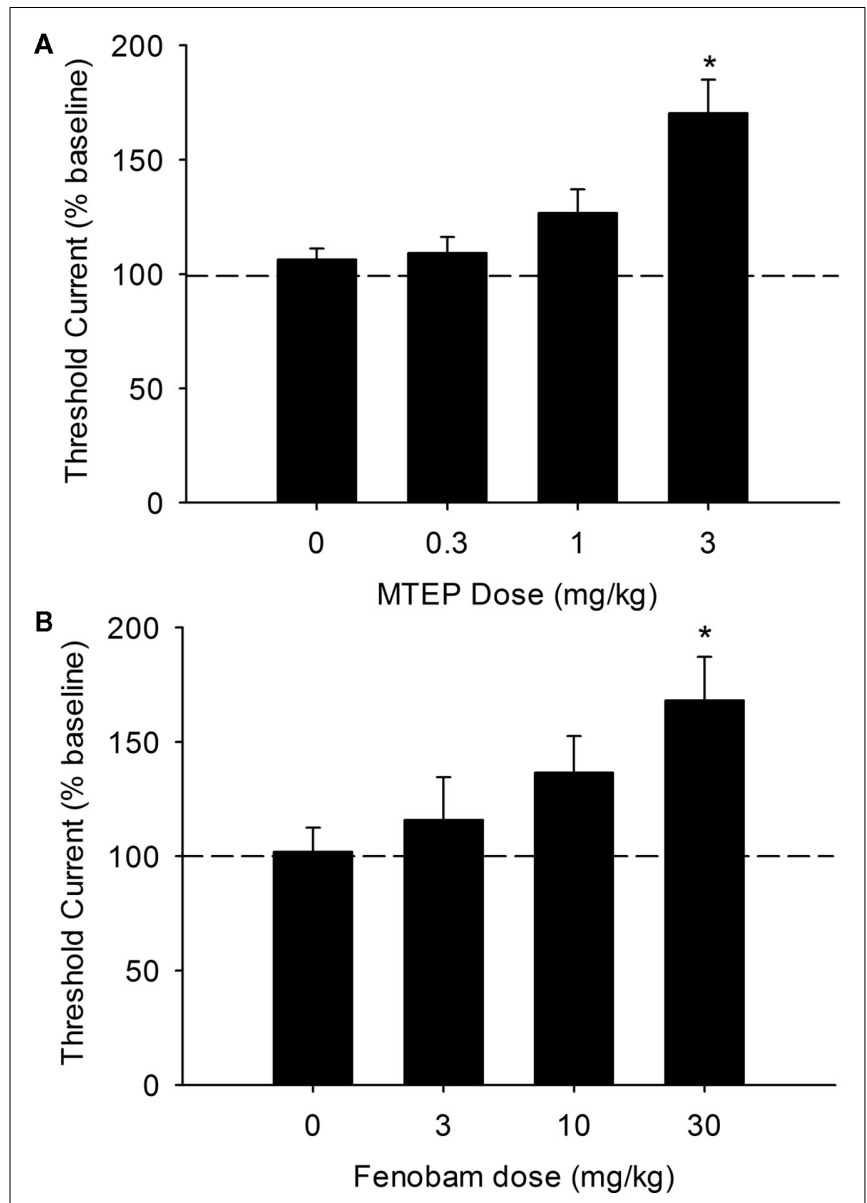

FIGURE 1 | Dose-dependent increases in ICSS thresholds following acute administration of the mGlu5 NAMs MTEP [(A): $n=13]$ or fenobam [(B): $\boldsymbol{n}=11]$. ${ }^{*} P<0.05$ vs. vehicle.

significantly lower than those observed during session 1. Similarly, a significant effect of session dose was observed in fenobam treated rats $\left[F_{(4,28)}=7.76, P<0.001\right]$, and post hoc analyses revealed that ICSS thresholds during sessions 2, 3, 4, and 5 were significantly lower than those during session 1. Repeated administration of vehicle $(10 \% \mathrm{v} / \mathrm{v})$ produced no effects on ICSS thresholds across sessions, and response latencies for all three treatment groups were unaffected (all Ps > 0.05).

\section{ELECTRODE PLACEMENT}

Examination of histological sections under bright microscopy demonstrated that three rats had incorrect placement of the ICSS electrode into the lateral hypothalamus. Data obtained from these animals were discarded. An additional seven rats were removed from the ICSS study due to loss of the cranial implant during the experiment. Tissue from all other animals demonstrated correct placement of the electrode.

\section{DISCUSSION}

Our findings indicate that positive and negative allosteric modulation of mGlu5 receptors differentially modulates brain reward

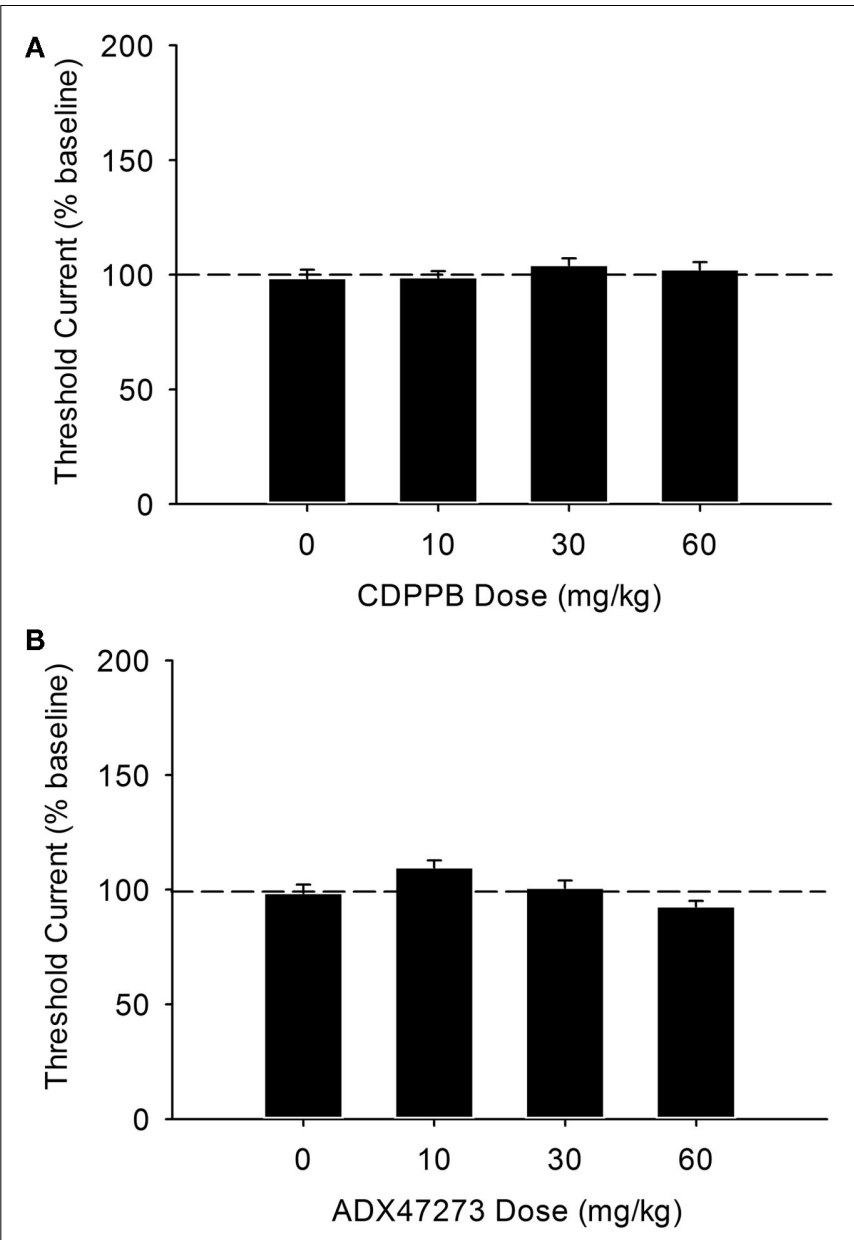

FIGURE 2 | Absence of effects of acute administration of various doses of the mGlu5 PAM CDPPB [(A): $n=15]$ or ADX47273 [(B): $n=15]$ on ICSS thresholds.

function as assessed by ICSS threshold determination procedures. Specifically, acute administration of the mGlu5 PAMs CDPPB and ADX47273 are without effect on ICSS thresholds, suggesting an absence of alteration in brain reward function. However, it should be noted that we tested doses up to $60 \mathrm{mg} / \mathrm{kg}$ of these mGlu5 PAMs, while other studies have shown that a median effective doses of $100 \mathrm{mg} / \mathrm{kg}$ ADX47273 was required to attenuate dopaminemediated behaviors such as apomorphine-induced climbing and phencyclidine-, apomorphine-, and amphetamine-induced hyperlocomotion (Liu et al., 2008). Thus, the possibility exists that doses of ADX47273 and CDPPB higher than $60 \mathrm{mg} / \mathrm{kg}$ may alter brain reward function, and further studies are needed to confirm this possibility.

In contrast to the lack of observed effects of acute administration of mGlu5 PAMs, acute administration of the mGlu5 NAMs MTEP and fenobam dose-dependently increased ICSS thresholds, which is reflective of decreased brain reward function (Kornetsky and Esposito, 1979; Kornetsky and Bain, 1992; Markou and Koob, 1992). These latter observations are in agreement with previous studies showing that acute administration of the less 


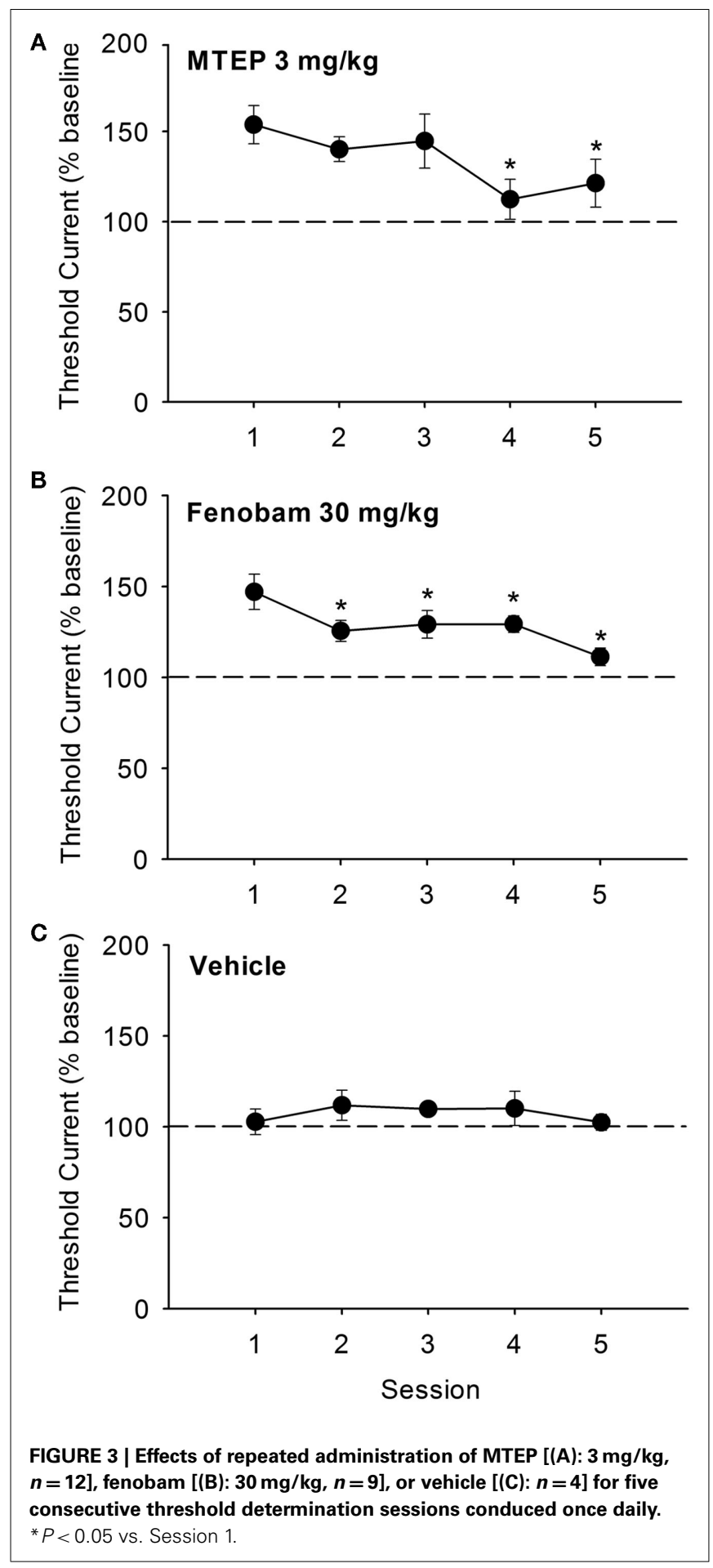

selective mGlu5 NAM MPEP ( 3 and $9 \mathrm{mg} / \mathrm{kg}$ ) also elevates ICSS thresholds (Harrison et al., 2002; Kenny et al., 2003, 2005). However, a more recent study found that these doses of MPEP did not alter brain stimulation reward (Gormley and Rompre, 2011). These discrepant results are likely due to differences in the ICSS procedures employed. In the present study and others (Harrison et al., 2002; Kenny et al., 2003, 2005), a current-intensity threshold determination procedure was used, which varies the intensity of the stimulation current delivered to the electrode while keeping the stimulation frequency constant. On the other hand, Gormley and Rompre (2011) utilized a rate-frequency analysis procedure which varies the frequency of the stimulation current delivered to the electrode while keeping the current-intensity constant. It is therefore of interest to conduct future studies to determine if MTEP or fenobam produce any effects on brain stimulation reward using this rate-frequency approach.

The fact that acute administration of MTEP and fenobam increased ICSS threshold suggests that the reported ability of these drugs to attenuate drug self-administration (Cowen et al., 2005, 2007; Adams et al., 2008; Osborne and Olive, 2008; Palmatier et al., 2008; Gass et al., 2009; Hao et al., 2010; Sidhpura et al., 2010) may result from decreases in baseline activity of the brain's reward circuitry. In addition, elevations in ICSS threshold are generally associated with aversive or anhedonic states (Markou and Koob, 1992). Thus, mGlu5 NAM-induced suppression of drug intake may reflect a negative affective state of the animal as opposed to a reduction in the reinforcing and motivational effects of the self-administered drug. These factors need to be taken into consideration when interpreting the underlying mechanisms by which mGlu5 NAMs reduce drug intake.

We also found when the doses of MTEP and fenobam that elevated ICSS thresholds following acute administration ( 3 and $30 \mathrm{mg} / \mathrm{kg}$, respectively) were administered repeatedly over the course of 5 days, a gradual attenuation of the ICSS thresholdelevating effects was observed. This development of tolerance may possibly be reflective of reduced expression of mGlu5 in forebrain regions that result from repeated mGlu5 NAM administration, as has previously been reported (Cowen et al., 2005). Regardless of the mechanism, since elevations in ICSS thresholds produced by MTEP and fenobam were significantly reduced after several days of treatment, it is of interest to discern whether repeated administration of either of these ligands results in tolerance to their ability to suppress drug intake. If tolerance to the potential therapeutic effects of MTEP or fenobam are absent, as has recently been reported with regards to the lack of ability of repeated fenobam administration to produce tolerance to its analgesic effects (Montana et al., 2011), it would therefore follow that repeated administration of mGlu5 NAMs may be a novel experimental approach to suppressing drug intake that circumvents the potential confounds of reduced brain reward function. Repeated drug administration also has greater face validity for pharmacotherapeutic approaches to reducing drug intake in human drug addicts than single dosing paradigms.

The ability of acute fenobam administration to increase ICSS thresholds, and the subsequent development of tolerance to these effects, has important clinical implications for medical conditions other than drug addiction. Fenobam was introduced more than 30 years ago as a potential novel non-benzodiazepine anxiolytic compound (Itil et al., 1978; Friedmann et al., 1980; Pecknold et al., 1980, 1982; Goldberg et al., 1983). However, these clinical trials were discontinued following reports of adverse dose-related side effects such as dizziness, paresthesias, sedation, and derealization. More recently, it has been demonstrated that lower doses of fenobam (50-150 mg/day) actually produces cognitive 
improvement in adult patients with Fragile X syndrome, with no CNS-related adverse side effects (Berry-Kravis et al., 2009). Additional reports of clinical efficacy and few side effects have been reported for other mGlu5 NAMs such as ADX10059 for the treatment of gastro-esophageal reflux disease (Keywood et al., 2009; Zerbib et al., 2011). With the possible exception of early studies with high doses of fenobam, clinical reports on fenobam administration to humans have not yet reported adverse side effects that would be consistent with decreased brain reward function, such as

\section{REFERENCES}

Adams, C. L., Cowen, M. S., Short, J. L., and Lawrence, A. J. (2008). Combined antagonism of glutamate mGlu5 and adenosine A2A receptors interact to regulate alcohol-seeking in rats. Int. J. Neuropsychopharmacol. $11,229-241$.

Besheer, J., Grondin, J. J., Cannady, R., Sharko, A. C., Faccidomo, S., and Hodge, C. W. (2010). Metabotropic glutamate receptor 5 activity in the nucleus accumbens is required for the maintenance of ethanol self-administration in a rat genetic model of high alcohol intake. Biol. Psychiatry 67, 812-822.

Berry-Kravis, E. M., Hessl, D., Coffey, S., Hervey, C., Schneider, A., Yuhas, J., Hutchison, J., Snape, M., Tranfaglia, M., Nguyen, D. V., and Hagerman, R. (2009). A pilot open-label singledose trial of fenobam in adults with fragile X syndrome. J. Med. Genet. $46,266-271$

Bird, M. K., Kirchhoff, J., Djouma, E., and Lawrence, A. J. (2008). Metabotropic glutamate 5 receptors regulate sensitivity to ethanol in mice. Int. J. Neuropsychopharmacol. $11,765-774$.

Bird, M. K., and Lawrence, A. J. (2009a). Group I metabotropic glutamate receptors: involvement in drugseeking and drug-induced plasticity. Curr. Mol. Pharmacol. 2, 83-94.

Bird, M. K., and Lawrence, A. J. (2009b). The promiscuous mGlu5 receptor a range of partners for therapeutic possibilities? Trends Pharmacol. Sci. 30, 617-623.

Chiamulera, C., Epping-Jordan, M. P., Zocchi, A., Marcon, C., Cottiny, C., Tacconi, S., Corsi, M., Orzi, F., and Conquet, F. (2001). Reinforcing and locomotor stimulant effects of cocaine are absent in mGluR5 null mutant mice. Nat. Neurosci. 4, 873-874.

Cleva, R. M., Hicks, M. P., Gass, J. T., Wischerath, K. C., Plasters, E. T., Widholm, J. J., and Olive, M. F. (2011). mGluR5 positive allosteric modulation enhances extinction learning following cocaine selfadministration. Behav. Neurosci. $125,10-19$.
Cleva, R. M., and Olive, M. F. (in press). Metabotropic glutamate receptors and drug addiction. Wiley Interdiscip. Rev. Membr. Transp. Signal.

Cosford, N. D., Tehrani, L., Roppe, J., Schwieger, E., Smith, N. D., Anderson, J., Bristow, L., Brodkin, J., Jiang, X., Mcdonald, I., Rao, S., Washburn, M., and Varney, M. A. (2003). 3-[(2-Methyl-1,3-thiazol-4yl)ethynyl]-pyridine: a potent and highly selective metabotropic glutamate subtype 5 receptor antagonist with anxiolytic activity. J. Med. Chem. 46, 204-206.

Cowen, M. S., Djouma, E., and Lawrence, A. J. (2005). The metabotropic glutamate 5 receptor antagonist 3-[(2-methyl-1,3thiazol-4-yl)ethynyl)-pyridine reduces ethanol self-administration in multiple strains of alcoholpreferring rats and regulates olfactory glutamatergic systems. J. Pharmacol. Exp. Ther. 315, 590-600.

Cowen, M. S., Krstew, E., and Lawrence, A. J. (2007). Assessing appetitive and consummatory phases of ethanol self-administration in C57BL/6J mice under operant conditions: regulation by mGlu5 receptor antagonism. Psychopharmacology (Berl.) 190, 21-29.

Cozzoli, D. K., Goulding, S. P., Zhang, P. W., Xiao, B., Hu, J. H., Ary, A. W., Obara, I., Rahn, A., AbouZiab, H., Tyrrel, B., Marini, C., Yoneyama, N., Metten, P., Snelling, C., Dehoff, M. H., Crabbe, J. C., Finn, D. A., Klugmann, M., Worley, P. F., and Szumlinski, K. K. (2009). Binge drinking upregulates accumbens mGluR5-Homer2PI3K signaling: functional implications for alcoholism. J. Neurosci. 29, 8655-8668.

Friedmann, C. T. H., Davis, L. J., Ciccone, P. E., and Rubin, R. T. (1980). Phase II double-blind controlled study of a new anxiolytic, fenobam (McN-3377) vs. placebo. Curr. Ther. Res. 27, 144-151.

Gass, J. T., and Olive, M. F. (2009a). Positive allosteric modulation of mGluR5 receptors facilitates extinction of a cocaine contextual memory. Biol. Psychiatry 65, 717-720.

anhedonia, dysphoria, or other negative affective states. Nonetheless, based on our current findings, future clinical studies should monitor for possible occurrence of these effects, and if such effects resolve with repeated dosing.

\section{ACKNOWLEDGMENTS}

This work was supported by Public Health Services grants AA013852, DA024355, and DA025606 from the National Institutes of Health of the United States.

Gass, J. T., and Olive, M. F. (2009b). Role of protein kinase $\mathrm{C}$ epsilon (PKCE) in the reduction of ethanol reinforcement due to mGluR5 antagonism in the nucleus accumbens shell. Psychopharmacology (Berl.) 204, 587-597.

Gass, J. T., Osborne, M. P., Watson, N. L., Brown, J. L., and Olive, M. F. (2009). mGluR5 antagonism attenuates methamphetamine reinforcement and prevents reinstatement of methamphetamine-seeking behavior in rats. Neuropsychopharmacology 34, 820-833.

Goldberg, M. E., Salama, A. I., Patel, J. B., and Malick, J. B. (1983). Novel non-benzodiazepine anxiolytics. Neuropharmacology 22, 1499-1504.

Gormley, S., and Rompre, P. P. (2011). Blockade of mGLUR5 receptors differentially alters amphetamineinduced enhancement of locomotor activity and of brain stimulation reward. J. Psychopharmacol. 25, 393-401.

Hao, Y., Martin-Fardon, R., and Weiss, F. (2010). Behavioral and functional evidence of metabotropic glutamate receptor $2 / 3$ and metabotropic glutamate receptor 5 dysregulation in cocaine-escalated rats: factor in the transition to dependence. Biol. Psychiatry 68, 240-248.

Harrison, A. A., Gasparini, F., and Markou, A. (2002). Nicotine potentiation of brain stimulation reward reversed by $\mathrm{DH} \beta \mathrm{E}$ and SCH 23390 , but not by eticlopride, LY 314582 or MPEP in rats. Psychopharmacology (Berl.) 160, 56-66.

Heidbreder, C. A., Bianchi, M., Lacroix, L. P., Faedo, S., Perdona, E., Remelli, R., Cavanni, P., and Crespi, F. (2003). Evidence that the metabotropic glutamate receptor 5 antagonist MPEP may act as an inhibitor of the norepinephrine transporter in vitro and in vivo. Synapse 50, 269-276.

Itil, T. M., Seaman, P. A., Huque, M., Mukhopadhyay, S., Blasucci, D., Tat, K., and Ciccone, P. E. (1978). The clinical and quantitative EEG effects and plasma levels of fenobam (McN$3377)$ in subjects with anxiety: an open rising dose tolerance and efficacy study. Curr. Ther. Res. 24, 708-724.

Kenny, P. J., Boutrel, B., Gasparini, F., Koob, G. F., and Markou, A. (2005). Metabotropic glutamate 5 receptor blockade may attenuate cocaine self-administration by decreasing brain reward function in rats. Psychopharmacology (Berl.) 179, 247-254.

Kenny, P. J., Gasparini, F., and Markou, A. (2003). Group II metabotropic and alpha-amino-3-hydroxy-5methyl-4-isoxazole propionate (AMPA)/kainate glutamate receptors regulate the deficit in brain reward function associated with nicotine withdrawal in rats. J. Pharmacol. Exp. Ther. 306, 1068-1076.

Kenny, P. J., and Markou, A. (2004). The ups and downs of addiction: role of metabotropic glutamate receptors. Trends Pharmacol. Sci. 25, 265-272.

Keywood, C., Wakefield, M., and Tack, J. (2009). A proof of concept study evaluating the effect of ADX10059, a metabotropic glutamate receptor5 negative allosteric modulator, on acid exposure and symptoms in gastro-esophageal reflux disease. Gut 58, 1192-1199.

Kinney, G. G., O’Brien, J. A., Lemaire, W., Burno, M., Bickel, D. J., Clements, M. K., Chen, T. B., Wisnoski, D. D., Lindsley, C. W., Tiller, P. R., Smith, S., Jacobson, M. A., Sur, C., Duggan, M. E., Pettibone, D. J., Conn, P. J., and Williams, D. L. Jr. (2005). A novel selective positive allosteric modulator of metabotropic glutamate receptor subtype 5 has in vivo activity and antipsychotic-like effects in rat behavioral models. J. Pharmacol. Exp. Ther. 313, 199-206.

Kornetsky, C., and Bain, G. (1992). Brain-stimulation reward: a model for the study of the rewarding effects of abused drugs. NIDA Res. Monogr. 124, 73-93.

Kornetsky, C., and Esposito, R. U. (1979). Euphorigenic drugs: effects on the reward pathways of the brain. Fed. Proc. 38, 2473-2476. 
Krystal, J. H., Mathew, S. J., D'Souza, D. C., Garakani, A., Gunduz-Bruce, H., and Charney, D. S. (2010). Potential psychiatric applications of metabotropic glutamate receptor agonists and antagonists. CNS Drugs 24, 669-693.

Lea, P. M., and Faden, A. I. (2006). Metabotropic glutamate receptor subtype 5 antagonists MPEP and MTEP. CNS Drug Rev. 12, 149-166.

Lindsley, C. W., Wisnoski, D. D., Leister, W. H., O'Brien, J. A., Lemaire, W., Williams, D. L. Jr., Burno, M., Sur, C., Kinney, G. G., Pettibone, D. J., Tiller, P. R., Smith, S., Duggan, M. E., Hartman, G. D., Conn, P. J., and Huff, J. R. (2004). Discovery of positive allosteric modulators for the metabotropic glutamate receptor subtype 5 from a series of N-(1,3-diphenyl-1H-pyrazol-5yl)benzamides that potentiate receptor function in vivo. J. Med. Chem. 47, 5825-5828.

Liu, F., Grauer, S., Kelley, C., Navarra, R., Graf, R., Zhang, G., Atkinson, P. J., Wantuch, C., Popiolek, M., Day, M., Khawaja, X., Smith, D., Olsen, M., Kouranova, E., Gilbert, A., Lai, M., Pausch, M. H., Pruthi, F., Pulicicchio, C., Brandon, N. J., Comery, T. A., Beyer, C. E., Logue, S., Rosenzweig-Lipson, S., and Marquis, K. L. (2008). ADX47273: a novel metabotropic glutamate receptor 5 selective positive allosteric modulator with preclinical antipsychoticlike and pro-cognitive activities. J. Pharmacol. Exp. Ther. 327, 827-839.

Markou, A., and Koob, G. F. (1992). Construct validity of a selfstimulation threshold paradigm: effects of reward and performance manipulations. Physiol. Behav. 51, 111-119.
Montana, M. C., Cavallone, L. F., Stubbert, K. K., Stefanescu, A. D., Kharasch, E. D., and Gereau, R. W. (2009). The metabotropic glutamate receptor subtype 5 antagonist fenobam is analgesic and has improved in vivo selectivity as compared to the prototypical antagonist 2-methyl6-(phenylethynyl)-pyridine. Pharmacol. Exp. Ther. 330, 834-843.

Montana, M. C., Conrardy, B. A., Cavallone, L. F., Kolber, B. J., Rao, L. K., Greco, S. C., and Gereau, R. W. T. (2011). Metabotropic glutamate receptor 5 antagonism with fenobam: examination of analgesic tolerance and side effect profile in mice. Anesthesiology 115, 1239-1250.

Nic Dhonnchadha, B. A., and Kantak, K. M. (2011). Cognitive enhancers for facilitating drug cue extinction: insights from animal models. Pharmacol. Biochem. Behav. 99, 229-244.

Niswender, C. M., and Conn, P. J. (2010). Metabotropic glutamate receptors: physiology, pharmacology, and disease. Annu. Rev. Pharmacol. Toxicol. 50, 295-322.

O’Leary, D. M., Movsesyan, V., Vicini, S., and Faden, A. I. (2000). Selective mGluR5 antagonists MPEP and SIB1893 decrease NMDA or glutamatemediated neuronal toxicity through actions that reflect NMDA receptor antagonism. Br. J. Pharmacol. 131, 1429-1437.

Olive, M. F. (2009). Metabotropic glutamate receptor ligands as potential therapeutics for drug addiction. Curr. Drug Abuse Rev. 2, 83-98.

Osborne, M. P. H., and Olive, M. F. (2008). A role for mGluR5 receptors in intravenous methamphetamine self-administration. Ann. N. Y. Acad. Sci. 1139, 206-211.

Palmatier, M. I., Liu, X., Donny, E. C., Caggiula, A. R., and Sved, A. F. (2008). Metabotropic glutamate 5 receptor (mGluR5) antagonists decrease nicotine seeking, but do not affect the reinforcement enhancing effects of nicotine. Neuropsychopharmacology 33, 2139-2147.

Paxinos, G., and Watson, C. (2007). The Rat Brain in Stereotaxic Coordinates. San Diego: Academic Press.

Pecknold, J. C., Mcclure, D. J., and Appeltauer, L. (1980). Fenobam in anxious outpatients. Curr. Ther. Res. 27, 119-123.

Pecknold, J. C., Mcclure, D. J., Appeltauer, L., Wrzesinski, L., and Allan, T. (1982). Treatment of anxiety using fenobam (a nonbenzodiazepine) in a double-blind standard (diazepam) placebo-controlled study. J. Clin. Psychopharmacol. 2, 129-133.

Porter, R. H., Jaeschke, G., Spooren, W., Ballard, T., Buettelmann, B., Kolczewski, S., Peters, J. U., Prinssen, E., Wichmann, J., Vieira, E., Muehlemann, A., Gatti, S. Mutel, V., and Malherbe, P. (2005). Fenobam: a clinically validated non-benzodiazepine anxiolytic is a potent, selective and noncompetitive mGlu5 receptor antagonist with inverse agonist activity. J. Pharmacol. Exp. Ther. 315, 711-721.

Sidhpura, N., Weiss, F., and MartinFardon, R. (2010). Effects of the mGlu2/3 agonist LY379268 and the mGlu5 antagonist MTEP on ethanol seeking and reinforcement are differentially altered in rats with a history of ethanol dependence. Biol. Psychiatry 67, 804-811.
Spooren, W. P., Gasparini, F., Salt, T. E., and Kuhn, R. (2001). Novel allosteric antagonists shed light on mglu5 receptors and CNS disorders. Trends Pharmacol. Sci. 22, 331-337.

Zerbib, F., Bruley, D. V. S., Roman, S., Tutuian, R., Galmiche, J. P., Mion, F., Tack, J., Malfertheiner, P., and Keywood, C. (2011). Randomised clinical trial: effects of monotherapy with ADX10059, a mGluR5 inhibitor, on symptoms and reflux events in patients with gastro-oesophageal reflux disease. Aliment. Pharmacol. Ther. 33, 911-921.

Conflict of Interest Statement: The authors declare that the research was conducted in the absence of any commercial or financial relationships that could be construed as a potential conflict of interest.

Received: 02 November 2011; paper pending published: 22 November 2011; accepted: 21 December 2011; published online: 06 January 2012.

Citation: Cleva RM, Watterson LR, Johnson MA and Olive MF (2012) Differential modulation of thresholds for intracranial self-stimulation by mGlu5 positive and negative allosteric modulators: implications for effects on drug selfadministration. Front. Pharmacol. 2:93. doi: 10.3389/fphar.2011.00093

This article was submitted to Frontiers in Neuropharmacology, a specialty of Frontiers in Pharmacology.

Copyright (c) 2012 Cleva, Watterson, Johnson and Olive. This is an open-access article distributed under the terms of the Creative Commons Attribution Non Commercial License, which permits noncommercial use, distribution, and reproduction in other forums, provided the original authors and source are credited. 